\title{
Applications of direct-to-consumer hearing devices for adults with hearing loss: a review
}

\author{
This article was published in the following Dove Press journal: \\ Clinical Interventions in Aging \\ 18 May 2017 \\ Number of times this article has been viewed
}

\author{
Vinaya Manchaiah ${ }^{1-4}$ \\ Brian Taylor ${ }^{5}$ \\ Ashley L Dockens' \\ Nicole R Tran' \\ Kayla Lane' \\ Mariana Castle' \\ Vibhu Grover'
}

'Department of Speech and Hearing Sciences, Lamar University, Beaumont, TX, USA; ${ }^{2}$ The Swedish Institute for Disability Research, Department of Behavioural Sciences and Learning, Linköping University, Linköping, Sweden; ${ }^{3}$ Audiology India, Mysore, ${ }^{4}$ Department of Speech and Hearing, School of Allied Health Sciences, Manipal University, Manipal, India; ${ }^{5}$ Taylor Audio LLC, Minneapolis, MN, USA

Correspondence: Vinaya Manchaiah Department of Speech and Hearing Sciences, Lamar University, PO Box 10076, Beaumont, TX 777I0, USA

$\mathrm{Tel}+\mathrm{I} 4098808927$

Fax +l 4098802265

Email vinaya.manchaiah@lamar.edu
Background: This systematic literature review is aimed at investigating applications of direct-to-consumer hearing devices for adults with hearing loss. This review discusses three categories of direct-to-consumer hearing devices: 1) personal sound amplification products (PSAPs), 2) direct-mail hearing aids, and 3) over-the-counter (OTC) hearing aids.

Method: A literature review was conducted using EBSCOhost and included the databases CINAHL, MEDLINE, and PsycINFO. After applying prior agreed inclusion and exclusion criteria, 13 reports were included in the review.

Results: Included studies fell into three domains: 1) electroacoustic characteristics, 2) consumer surveys, and 3) outcome evaluations. Electroacoustic characteristics of these devices vary significantly with some meeting the stringent acoustic criteria used for hearing aids, while others producing dangerous output levels (ie, over 120-dB sound pressure level). Low-end (or low-cost) devices were typically poor in acoustic quality and did not meet gain levels necessary for most adult and elderly hearing loss patterns (eg, presbycusis), especially in high frequencies. Despite direct-mail hearing aids and PSAPs being associated with lower satisfaction when compared to hearing aids purchased through hearing health care professionals, consumer surveys suggest that $5 \%-19 \%$ of people with hearing loss purchase hearing aids through direct-mail or online. Studies on outcome evaluation suggest positive outcomes of OTC devices in the elderly population. Of note, OTC outcomes appear better when a hearing health care professional supports these users.

Conclusion: While some direct-to-consumer hearing devices have the capability to produce adverse effects due to production of dangerously high sound levels and internal noise, the existing literature suggests that there are potential benefits of these devices. Research of directto-consumer hearing devices is limited, and current published studies are of weak quality. Much effort is needed to understand the benefits and limitations of such devices on people with hearing loss.

Keywords: hearing loss, presbycusis, age-related hearing loss, hearing aids, direct-toconsumer, personal sound amplification product, direct-mail hearing aids, over-the-counter hearing aids

\section{Abbreviations}

ANSI, American National Standard Institute; BTE, behind-the-ear hearing aid; EIN, equivalent input noise; FDA, US Food and Drug Administration; KEMAR, Knowles Electronics Mannequin for Acoustic Research; OSPL90, output sound pressure level for 90-dB input SPL; OTC, over-the-counter; PCAST, President's Council of Advisors on Science and Technology; PSAP, personal sound amplification product; SPL, sound pressure level; THD, total harmonic distortion. 


\section{Introduction}

\section{Hearing loss and its management}

According to the World Health Organization (WHO), hearing loss is the fifth leading cause of years lived with disability. ${ }^{1}$

Research has shown that untreated hearing loss in adults has been linked to cognitive decline, ${ }^{2}$ depression, ${ }^{3}$ social isolation, ${ }^{4}$ increased incidence of dementia, ${ }^{5}$ and even falls. ${ }^{6}$ Prevalence of hearing loss highly correlates with increasing age. As of 2012, of those 65 years and older, 164.5 million persons $(-33 \%)$ reported disabling hearing loss. ${ }^{7}$ The number of individuals in this age group (65 and older) is growing at an exponentially faster rate ( $\sim 37 \%$ growth from 2010 to 2019) than younger age groups. ${ }^{8}$ Given this growth of the aging population, experts recognize untreated presbycusis as a looming public health concern. ${ }^{9,10}$

Historically, hearing aids have been the primary remediation option for individuals affected by medically uncomplicated presbycusis (ie, age-related hearing loss). Uptake of hearing aids, especially among adults, however, has been poor. Data from the US indicate that the unmet need for hearing health care is high, yielding between $67 \%$ and $86 \%$ of adults with hearing loss who fail to use hearing aids. ${ }^{10}$ One study demonstrated that less than $25 \%$ of adults aged 80 and above with self-reported hearing problems - the cohort with the highest prevalence of hearing loss - do not use hearing aids. ${ }^{11}$

The reasons for poor hearing aid uptake among adults are myriad. In the US, approximately 20 million persons 60 years or older have an untreated clinically significant hearing loss, of which nearly 6 million are of low income. ${ }^{12}$ These figures may suggest that there is a substantially large population of individuals, even in high-income countries, who may have difficulty paying for high-priced hearing care services. While hearing aids are often not reimbursed by health insurance and high costs are a primary issue, finances are not the only barrier and reason for poor uptake. Other explanations for poor uptake include stigma, negative word-of-mouth about hearing aids, and the inconvenience of multiple appointments with hearing health care professionals..$^{13}$

\section{Direct-to-consumer approach in health care}

While the audiology community and those they serve have attended to issues related to the effects of untreated hearing loss and poor hearing aid uptake, health care has undergone a consumer-driven revolution. Popularity is growing for a direct-to-consumer approach to health care service delivery, which is believed to provide greater accessibility to services and affordability for patients. The need for a direct-to-consumer approach has also been discussed in relation to hearing care service delivery. Contrera et al ${ }^{14}$ outlined five major obstacles for obtaining effective hearing and rehabilitative care, which included awareness, access, treatment options, cost, and device effectiveness. A directto-consumer delivery model could partially address these obstacles (eg, access and cost).

\section{Direct-to-consumer hearing devices}

Led by the baby-boomer generation and access to low-cost, high-tech smartphones, consumers are demanding to be more actively involved in their health care decisions. Over the past few years, the increase in computing capacity of technology (eg, smartphones) has led experts to believe that health care will become more accessible and affordable through these technologies.

Undoubtedly, this democratization of health care is already having an impact on the hearing health care industry. This has led to a proliferation of amplification devices that are available on the market today, as shown in Table 1. Similar to traditional hearing aids regulated since the 1970 s by the FDA, a variety of hearing technologies can be purchased through direct-mail, via the Internet, or OTC with minimal involvement from a hearing care professional. Increased processing in technologies has led to a rise of self-programming

Table I Differences and similarities between hearing aids, direct-mail and OTC hearing aids, PSAPs, and hearing apps

\begin{tabular}{lllll}
\hline & $\begin{array}{l}\text { Traditional } \\
\text { hearing aids }\end{array}$ & $\begin{array}{l}\text { OTC hearing aids/ } \\
\text { direct-mail hearing aids }\end{array}$ & PSAPs & $\begin{array}{l}\text { Smartphone-based } \\
\text { amplification apps }\end{array}$ \\
\hline Regulated under FDA & Yes & Yes & No & No \\
Professional consultation needed & Yes & No & No & No \\
Average price range per device (in US \$) & $\mathrm{I}, 000-5,000$ & $200-500$ & $20-400$ & $0-10$ \\
Intended target group & $\mathrm{PHL}$ & $\mathrm{PHL}$ & $\mathrm{PNH}$ & $\mathrm{PNH}$ \\
Intended user & $\mathrm{PHL}$ & $\mathrm{PHL}$ & $\mathrm{PNH}$ & $\mathrm{PHL}$ and PNH \\
Typical consumer image & Stigmatizing & Stigmatizing & Stigmatizing to mass appeal & Mass appeal \\
\hline
\end{tabular}

Abbreviations: OTC, over-the-counter; PSAPs, personal sound amplification products; FDA, US Food and Drug Administration; PHL, person with hearing loss; $\mathrm{PNH}$, person with normal hearing. 
hearing aids, which enable end users to fit and program their own hearing aid without assistance from a hearing care professional. One recent feasibility study of self-programming hearing aids showed that $73 \%$ of older adults were able to successfully insert these devices into their ears, and $55 \%$ of these same adults could complete a 10 -step fitting process without the assistance of a professional. ${ }^{15}$

Direct-to-consumer amplification is not confined to traditional hearing aids. Recently, there has been a dramatic increase in the number of PSAPs that can be purchased online or in retail stores. Unregulated by the FDA, PSAPs can be purchased by consumers directly from multiple manufacturers without involvement of a licensed hearing care professional. ${ }^{16}$ In addition to a wide range of prices (US \$20 to over \$400), PSAPs have a varying range of quality, with a few operating electroacoustically similar to traditional hearing aids, according to one recent study. ${ }^{17}$ There are various advantages and limitations of current PSAPs. ${ }^{18,19}$ Additionally, since FDA regulations have not kept pace with technological innovations, the same company can manufacture both traditional hearing aids and PSAPs. Thus, an identical product may have two different labels, hearing aid and PSAP, leading to confusion for both consumers and professionals.

Beyond PSAPs, there are a few other types of direct-toconsumer hearing devices. One, broadly classified as hearables, is paired to smartphones and includes several features, such as biometrics, music storage, hearing protection, and amplification into a device worn in the ear. ${ }^{16,20,21}$ Another such technology is smartphone-enabled amplification applications (apps). These two types of devices are not addressed in the current review.

\section{Definitions}

The FDA defines a PSAP as a wearable consumer electronic product intended for consumers without hearing loss to amplify sounds in certain environments such as recreational activities. PSAPs come in a range of style options, from those similar to Bluetooth headsets to those almost identical to in-the-ear or behind-the-ear hearing aids. While PSAPs are direct-to-consumer products, it is important to note that per the FDA, PSAPs are not intended to compensate for impaired hearing (eg, cannot treat, cure, or mitigate disease nor alter the structure or function of the body). For this reason, the FDA refrains from asserting regulatory authority over them, except incidentally under the Radiation Control for Health and Safety Act of 1968. This act applies to all sound amplification equipment, and among others, seeks to ensure that there are volume limits to prevent hearing damage.
The FDA defines a hearing aid as any wearable instrument or device designed for, offered for the purposes of, or represented as aiding persons with or compensating for impaired hearing. All hearing aids must comply with specific requirements of the FDA. On the other hand, the FDA regulates OTC hearing aids. The main difference between a traditional hearing aid and an OTC hearing aid is that the OTC device is considered a direct-to-consumer product. Thus, it does not require consultation with or dispensing from a hearing health care professional, although the FDA requires that a person buying a hearing aid be examined to rule out certain red-flag medical conditions related to the ears or that a medical waiver declining a medical evaluation be signed by the patient. OTC hearing aids are also often referred to as direct-mail hearing aids.

Other than the lack of FDA regulation, the main difference between PSAP and OTC devices is the intended use of the device. As of now, PSAPs are intended to be used by people with normal hearing who want an enhancement of certain environmental sounds. However, the OTC hearing aids are directed towards people with mild-to-moderate hearing loss to improve their hearing and communication.

\section{Potential regulatory changes}

Two separate organizations that advise the American federal government (ie, PCAST and National Academies of Sciences, Engineering, and Medicine) recently recognized that PSAPs and OTC devices may play a crucial role in addressing unmet needs of adults with untreated presbycusis. ${ }^{22}$ Given both the potential changes to FDA regulations and the rapid pace of innovation in amplification technology, this systemic literature review investigates the current published findings regarding these devices with the secondary purpose of uncovering questions within this area of emerging consumer-driven amplification that warrant further study. A recent paper by Blustein and Weinstein provides more details on the regulatory changes recommended by the PCAST. ${ }^{23}$

The current literature review is aimed at investigating the applications of direct-to-consumer hearing devices for adults with hearing loss. In this review, we focus on three categories of direct-to-consumer hearing devices: PSAPs, direct-mail hearing aids, and OTC hearing aids.

\section{Method}

A literature search was conducted from October to December 2016 through EBSCOhost, which offers customizable basic and advanced searching supported by Boolean logic, natural language, enhanced subject indexing, and 
journal searching. This database includes various other databases. However, our search was limited to three databases: CINAHL, MEDLINE, and PsycINFO. Two authors conducted the search independently to ensure that no existing literature in this area had been missed.

\section{Search words}

The search was conducted with the following words/phrases: cheap hearing aids, personal sound amplification systems, personal sound amplification products (PSAPs), personal sound amplification devices, direct-mail hearing aids, overthe-counter (OTC) hearing aids, direct-to-consumer hearing aids, direct-to-consumer hearing devices, hearing amplifier, sound amplifier, basic hearing aid, self-fitting hearing aid, affordable hearing aid, and hearable(s).

\section{Inclusion and exclusion criteria}

Due to limited numbers of studies in this area, all studies published in peer-reviewed journals and reports from nonpeer-reviewed journals/magazines were included in the review regardless of their study design, as long as they met inclusion criteria. Papers were excluded if the study did not meet the following criteria:

1. Population - adults with hearing loss

2. Condition - electroacoustic characteristics, consumer market surveys, and outcome studies

3. Context-studies focusing on direct-to-consumer hearing devices
4. Study type - any study design

5. Language - studies that were published in English

6. Timescale - no restrictions were applied

Overall, the database search resulted in a total of 213 records of articles. A manual search was also conducted through conference papers and through reference lists of key papers, and an additional 21 reports were identified. Abstracts of all the 234 records were screened, and subsequently, full text of 25 reports was assessed for eligibility. After applying inclusionary criteria, 13 studies were found to be relevant to include in the current review. Figure 1 shows the process followed in study identification, eligibility screening, and inclusion of papers.

\section{Summary of studies on direct-to- consumer hearing devices}

Table 2 provides a summary of these studies included in this literature review. Literature searches resulted in a total of 13 reports concerning direct-to-consumer hearing devices, including five peer-reviewed journal articles, four peerreviewed magazine articles, three consumer surveys, and one conference paper.

\section{Electroacoustic characteristics}

The literature search identified four published reports on electroacoustic characteristics, three peer-reviewed publications that focused on OTC hearing, ${ }^{24-26}$ and one with emphasis on PSAPs, published in a non-peer-reviewed professional

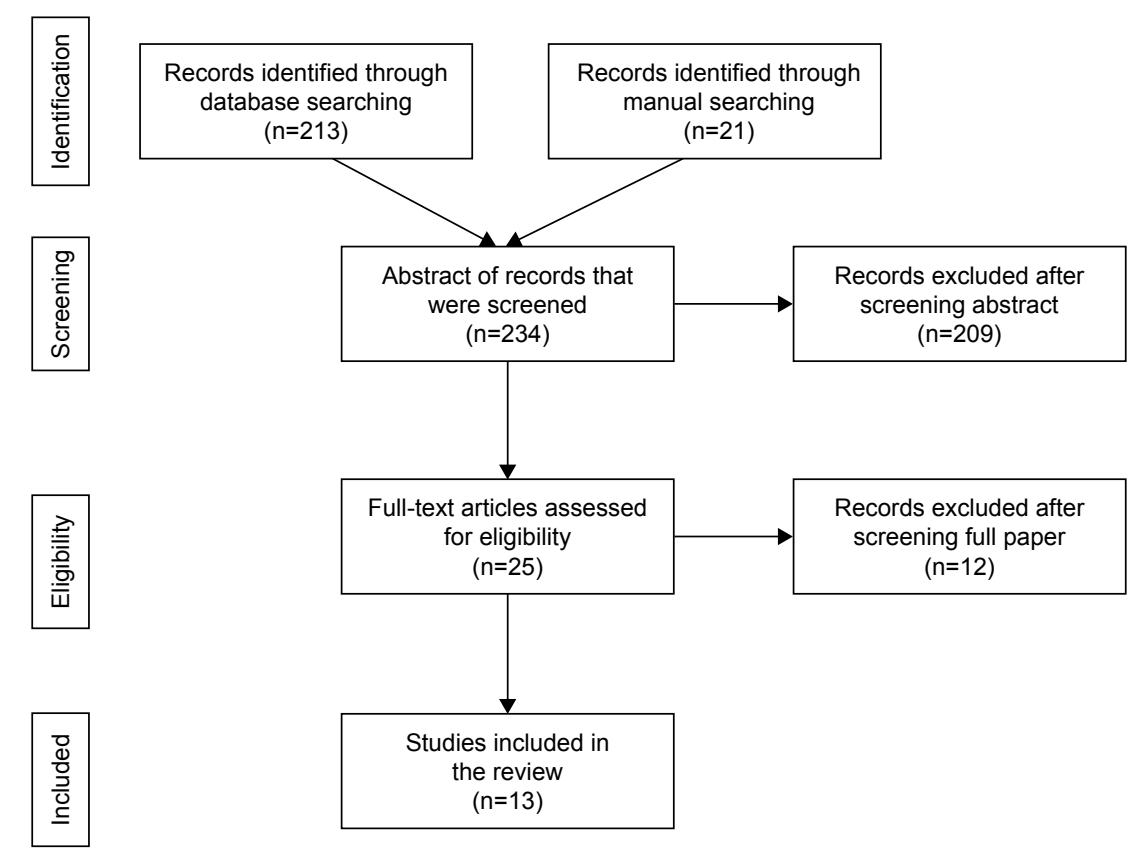

Figure I Flow diagram of the study identification, eligibility search, and inclusion process. 
Table 2 Studies on direct-to-consumer hearing devices

\begin{tabular}{|c|c|c|c|}
\hline Study & $\begin{array}{l}\text { Publication } \\
\text { type }\end{array}$ & Aim/design & Key findings and observations \\
\hline \multicolumn{4}{|c|}{ Electroacoustic characteristics } \\
\hline $\begin{array}{l}\text { Cheng and } \\
\text { McPherson }{ }^{24}\end{array}$ & $\begin{array}{l}\text { Peer-reviewed } \\
\text { journal }\end{array}$ & $\begin{array}{l}\text { Examined the amplification } \\
\text { characteristics of ten low-cost } \\
(\leq \text { US } \$ 65) \text { OTC devices }\end{array}$ & $\begin{array}{l}\text { Performance of majority of OTC devices was within ANSI } \\
\text { standard limit for typical HA, although some were outside the } \\
\text { limit for EIN and THD. Overall, OTC devices were low-gain } \\
\text { hearing devices with little-to-no-high frequency output. }\end{array}$ \\
\hline & & $\begin{array}{l}\text { This laboratory study used } \\
\text { ANSI S3.22 standard for test } \\
\text { box assessments and real-ear } \\
\text { measurements on ten normal } \\
\text { hearing adults }\end{array}$ & $\begin{array}{l}\text { Devices deemed unable to meet needs of the majority of older } \\
\text { adults with presbycusis who are likely the more common OTC } \\
\text { device users. Researchers suggested that only patients with } \\
\text { mild-to-moderate low-frequency reverse sloping HLs (eg, early } \\
\text { Meniere's disease or otosclerosis) may benefit from use. }\end{array}$ \\
\hline Callaway and Punch ${ }^{25}$ & $\begin{array}{l}\text { Peer-reviewed } \\
\text { journal }\end{array}$ & $\begin{array}{l}\text { Aimed to determine the } \\
\text { appropriateness of eleven OTC } \\
\text { devices (two low cost [ }<\text { US } \\
\$ 100 \text { ] and eight mid cost [US } \\
\$ 100-500] \text { ) for mild-to-moderate } \\
\text { high-frequency HL, moderate-to- }\end{array}$ & $\begin{array}{l}\text { Reference test and FOG values were the same for each of } \\
\text { the eleven OTC devices. Any volume control position below } \\
\text { full-on volume could not produce gain at least } 17 \mathrm{~dB} \text { below } \\
\text { OSPL90. Gain across nine of the devices was focused on low- } \\
\text { frequency regions. Low-range and mid-range devices varied } \\
\text { greatly. }\end{array}$ \\
\hline
\end{tabular}

moderately severe sloping $\mathrm{HL}$,

and flat moderate $\mathrm{HL}$

Descriptive technical study.

Laboratory ANSI S3.22

standard test box assessments

performed twice, 2 months

apart. Test-retest $<5 \mathrm{~dB}$ for

all measurements in eight

OTC devices

Chan and McPherson ${ }^{26}$ Peer-reviewed Follow-up study to determine if the journal amplification characteristics of lowcost ( $\leq$ US \$II5) OTC device have changed over a decade Laboratory ANSI S3.22-2009 standards were used for test box assessments and real-ear measurements on a simulated condition using a KEMAR

Smith et al ${ }^{17}$

Peer-reviewed Evaluated low-end and high-end magazine PSAPs and HAs amplification characteristics

Laboratory ANSI S3.22-2009 standards were used for test box assessments and real-ear measurements on a simulated condition using a KEMAR

Survey of consumers Kochkin ${ }^{27}$

Peer-reviewed Aimed at estimating the population magazine

of PHL who use direct-mail HAs and PSAPs and also to compare the characteristics of those who use one-size-fits-all products with those who use custom HAs

Used a cross-sectional survey design and consisted sample of $3174 \mathrm{HA}$ owners and 4339 non-adopters of HAs
Mid-range OTC devices met the gain and output targets to a greater extent than the low-range devices. In addition, low-range devices had high EIN, which may result in safety hazard. Hence, low-range OTC devices appear to be electroacoustically inadequate, whereas mid-range devices appear to potentially be useful for people with mild-tomoderate $\mathrm{HL}$.

Electroacoustic characteristics of OTC devices were similar to their earlier study performed over 10 years prior (ie, Cheng and McPherson ${ }^{24}$ ).

Some of the OTC devices were able to match the target gains in simulated conditions, although authors suggest that the factors such as ineffective volume control function, high internal noise, and irregular frequency response may limit the potential benefit to people with HL.

All high-end HAs were able to fit most $\mathrm{HL}$ configurations, whereas two high-end PSAPs and one app were able to meet the moderate $\mathrm{HL}$ configuration.

Most low-end HAs and PSAPs produced inappropriately high gain at low frequencies, whereas high-end devices produced appropriate amplification for moderate $\mathrm{HL}$ configurations. Low-end PSAPs and HAs were found to be inappropriate for any severity and configuration of high-frequency HL.

Estimates suggested that about $3.3 \%$ of the HA owners received their device through direct-mail orders. PSAP owners were found to be $4.8 \%$ of the non-adopters population. PSAP owners paid less than US $\$ 50$ for their device when compared to direct-mail HA owners who paid a median of US $\$ 237$.

Direct-mail and PSAP owners earned US $\$ 10,000$ less per year, were less likely to buy binaural HAs, and used devices less (ie, 3 hours a day when compared to 10 hours a day) than those who purchased custom HAs.

Nearly $75 \%$ of direct-mail and PSAP owners were candidates for custom HAs, although estimates suggested that $<18 \%$ users substitute PSAPs for custom HAs. 
Table 2 (Continued)

\begin{tabular}{lll}
\hline Study & $\begin{array}{l}\text { Publication } \\
\text { type }\end{array}$ & Aim/design \\
\hline Kochkin $^{31}$ & $\begin{array}{ll}\text { Peer-reviewed } \\
\text { magazine }\end{array}$ & $\begin{array}{l}\text { Compared the consumer } \\
\text { satisfaction, subjective benefit, and } \\
\end{array}$ \\
& quality-of-life changes associated \\
& with traditional and direct-mail HAs \\
& The study used a cross-sectional \\
& survey design. Sample included \\
& I,72I traditional HA owners and \\
& 2,332 direct-mail HA owners
\end{tabular}

Key findings and observations

Nearly half (45\%) of direct-mail HA consumers have previously tried or owned traditional HAs and have HL profile that is not dissimilar to typical HA user.

Direct-mail HA owners are older, are more likely to be retired, have lower income, more experienced $\mathrm{HA}$ user, and more likely to use one HA when compared to traditional HA owners.

Consumers believe that both direct-mail and traditional HAs provide equal benefit resulting in higher perceived value. Direct-mail users are more positive towards their device. Direct-mail HAs provided about average benefit, but significantly less real-world benefit than HAs dispensed by those with professionals who adhere to highest levels of best practice. However, consumers were willing to make trade-offs in benefit for substantial cost reduction.

Consumer Electronic Association $^{28}$

JapanTrak ${ }^{29}$

$\operatorname{JapanTrak}^{30}$

Outcome evaluation McPherson and Wong ${ }^{32}$
Consumer survey report

Consumer survey report

Consumer survey report

Peer-reviewed journal
Market research aimed at exploring the various situations in which PSAP users benefit from useage

Study used a cross-sectional Internet-based survey design and included a national sample of 3,459 US adults who had at least little trouble hearing

Aimed at understanding the $\mathrm{HL}$ prevalence rates and $\mathrm{HA}$ adoption rates. Also explored hearing device usage and demographics Market survey designed and executed by Anovum (Zurich) on behalf of Japan Hearing Instruments Manufacturers Association Representative sample of 15,036 with I,348 having $\mathrm{HL}$ (of which 450 were HA owners) Aimed at understanding the $\mathrm{HL}$ prevalence rates and $\mathrm{HA}$ adoption rates. Also explored hearing device usage and demographics Representative sample of 14,316 with I,306 having $\mathrm{HL}$ (of which 416 were HA owners)

Studied differences in self-reported benefit between conventional HAs and OTC devices Prospective open trial 19 older (63-83 years) adults with mild-to-moderate $\mathrm{HL}$
Only a fraction of those diagnosed with $\mathrm{HL}(6 \%)$ and those with at least some trouble hearing (4\%) own PSAPs, although two out of five are interested in purchasing direct-to-consumer hearing devices.

Although most consumers with trouble hearing would consult hearing care professional, few were interested in seeking information online (14\%), from friends and family (13\%), and others with hearing difficulties (10\%). More than two-thirds of the sample preferred purchasing nonprescription hearing devices (ie, mail or drug stores). Current PSAP owners mainly used them for listening to TV, although potential buyers were interested in exploring its use for wider situations.

$\mathrm{HL}$ prevalence in representative sample was $10.9 \%$, and $14.1 \%$ of $\mathrm{PHL}$ have $\mathrm{HAs}$ with more severe degree of $\mathrm{HL}$ indicated higher adoption rates.

$14 \%$ from direct-mail or online, $18 \%$ of $\mathrm{HA}$ owners purchased from an optical shop, and $56 \%$ from hearing health care professional.

$\mathrm{HL}$ prevalence in representative sample was $1 \mathrm{I} .3 \% \mathrm{PHL}$, and $13.5 \%$ having HAs and use of HAs resulted in significant improvement in quality of life.

$19 \%$ from direct-mail or online, $14 \%$ of HA owners purchased it from an optical shop, and $49 \%$ from hearing health care professional.

Satisfaction with HAs purchased online is lower than purchased in HA centers.

No significant differences in self-reported benefit scores between device types.

Concluded that affordable, OTC devices provide a potential opportunity for greater numbers of PHL to access amplification and benefit from improved communicative abilities. 
Table 2 (Continued)

\begin{tabular}{|c|c|c|c|}
\hline Study & $\begin{array}{l}\text { Publication } \\
\text { type }\end{array}$ & Aim/design & Key findings and observations \\
\hline \multirow[t]{3}{*}{ Sacco et $\mathrm{al}^{33}$} & $\begin{array}{l}\text { Peer-reviewed } \\
\text { journal }\end{array}$ & $\begin{array}{l}\text { Studied the clinical value of OTC } \\
\text { devices }\end{array}$ & $\begin{array}{l}\text { Use of OTC devices resulted in improvement in various } \\
\text { domains of hearing in quiet and noisy situations, improved } \\
\text { communication, and decreased negative emotions. }\end{array}$ \\
\hline & & Prospective open trial & Acceptability of the device was low to moderate. \\
\hline & & $\begin{array}{l}31 \text { older }(60+) \text { adults with mild-to- } \\
\text { moderate } \mathrm{HL}\end{array}$ & $\begin{array}{l}\text { Concluded that TEO First }{ }^{\circledR} \text { is an effective OTC device that } \\
\text { improved patients' quality of life. }\end{array}$ \\
\hline \multirow[t]{3}{*}{ Xu et $\mathrm{al}^{34}$} & $\begin{array}{l}\text { Conference } \\
\text { paper }\end{array}$ & $\begin{array}{l}\text { Examined the preferences of PSAPs } \\
\text { and HAs via listening to different } \\
\text { sounds processed by these devices }\end{array}$ & $\begin{array}{l}\text { In laboratory settings, PSAPs performed as well as HAs for } \\
\text { everyday noises and music. }\end{array}$ \\
\hline & & $\begin{array}{l}\text { Cross-sectional comparison study } \\
\text { conducted in a laboratory }\end{array}$ & HAs were significantly more preferred than PSAPs for speech. \\
\hline & & $\begin{array}{l}23 \text { adults ( } 23-83 \text { years) with } \\
\text { mild-to-moderate HL }\end{array}$ & $\begin{array}{l}\text { Different devices process some types of sounds more } \\
\text { effectively than other types of sounds. }\end{array}$ \\
\hline \multirow[t]{2}{*}{ Tedeschi and $\mathrm{Kihm}^{35}$} & $\begin{array}{l}\text { Peer-reviewed } \\
\text { magazine }\end{array}$ & $\begin{array}{l}\text { Pilot study examined the } \\
\text { outcome of direct-to-consumer } \\
\text { hearing devices with and without } \\
\text { professional guidance }\end{array}$ & $\begin{array}{l}\text { Some of the participants ( } 13 \%) \text { were not able to self-identify } \\
\text { the red-flag conditions that would require medical } \\
\text { consultation, nearly half were not able to correctly self-assess } \\
\text { the degree of loss, and nearly a third of the participants } \\
\text { with moderate loss could have delayed seeking help with } \\
\text { professionals. }\end{array}$ \\
\hline & & $\begin{array}{l}29 \text { older people (aged } 60 \text { or older) } \\
\text { with mild-to-moderate HL who } \\
\text { used PSAPs and provided outcome } \\
\text { data through survey after } 3 \text { and } \\
6 \text { weeks }\end{array}$ & $\begin{array}{l}\text { Individuals supported by hearing health care professionals } \\
\text { experienced better outcomes in terms of various indicators, } \\
\text { which include daily usage, expectations, overall satisfaction, } \\
\text { usage, willingness to recommend, and perceived success. }\end{array}$ \\
\hline
\end{tabular}

Abbreviations: OTC, over-the-counter; ANSI, American National Standard Institute; HA, hearing aid; EIN, equivalent input noise; THD, total harmonic distortion; $\mathrm{HL}$, hearing loss; FOG, full-on gain; OSPL90, output sound pressure level for 90-dB input sound pressure level; KEMAR, Knowles Electronics Mannequin for Acoustic Research; PSAP, personal sound amplification product; PHL, people with hearing loss.

magazine. ${ }^{17}$ Table 3 provides a summary of electroacoustic characteristics of PSAPs and OTC devices based on the published reports. Studies have reported values for OSPL90, THD, high-frequency average full-on gain, EIN, frequency range, and expected battery life. Of note, OSPL90, THD, and EIN are considered to be the most important indicators of quality of the device. The ANSI provides specification for such hearing aid characteristics. The studies included in this review have generally used ANSI S3.22 standards to compare electroacoustic data.

OSPL90 is the level of output provided by a hearing device when the input is set to 90-dB SPL and with full-on gain. ANSI S3.22 tolerances for OSPL90 are expected to be within $\pm 4 \mathrm{~dB}$ of the value provided by the manufacturer's

Table 3 Summary of electroacoustic characteristics of PSAPs and OTC devices based on published reports

\begin{tabular}{|c|c|c|}
\hline Characteristics & $\begin{array}{l}\text { PSAPs } \\
\left.\text { (Smith et } \mathrm{al}^{17}\right)\end{array}$ & $\begin{array}{l}\text { OTC hearing aids (Cheng and McPherson; }{ }^{24} \\
\text { Callaway and Punch; }{ }^{25} \text { Chan and McPherson }{ }^{26} \text { ) }\end{array}$ \\
\hline \multicolumn{3}{|l|}{ OSPL90 } \\
\hline Peak frequency $(\mathrm{Hz})$ & Not reported & $200-2,000$ ( $1,400-2,000$ more often $)$ \\
\hline Peak SPL (dB SPL) & Not reported & $105.6-133$ \\
\hline \multicolumn{3}{|l|}{ \%THD } \\
\hline $500 \mathrm{~Hz}$ & $0-3.97$ & $0.1-6.6$ (outliers I5.6 and 23.5) \\
\hline $800-\mathrm{I}, 000 \mathrm{~Hz}$ & $0.02-3.26$ & $0.1-9.7$ (outliers 30.0 and 46.5 ) \\
\hline $\mathrm{I}, 600-2,000 \mathrm{~Hz}$ & $0-2.07$ & $0.1-4.6$ (outliers I0.I and I0.8) \\
\hline HFA FOG (dB) & Not reported & $2.4-52.8$ \\
\hline EIN $(d B)$ & $23.85-54.48$ & $19.8-52.9$ \\
\hline Frequency range $(\mathrm{Hz})$ & Not reported & $<200$ (low) to 8,000 (high) \\
\hline Battery life (hours) & Not reported & $37-194$ hours \\
\hline
\end{tabular}

Abbreviations: PSAPs, personal sound amplification products; OTC, over-the-counter; OSPL90, output sound pressure level for 90-dB input SPL; SPL, sound pressure level; THD, total harmonic distortion; HFA FOG, high-frequency average full-on gain; EIN, equivalent input noise. 
specification sheet. However, in many of the studies discussed, the manufacturers of direct-to-consumer devices did not provide specification information. Most of the OTC devices were reported to have an output OSPL90 of 110- to $120-\mathrm{dB}$ SPL, although some were over 130-dB SPL. Although high gains over 130-dB SPL can be useful for greater degrees of hearing loss, this can be problematic for direct-to-consumer purchase; it creates potential issues such as feedback, noise damage, and so on. Peak responses ranged between 200 to $2,000 \mathrm{~Hz}$, although more close observation revealed peak values ranging between 1,400 and $2,000 \mathrm{~Hz}$. The frequency response curve showed a range of up to $8,000 \mathrm{~Hz}$ (higher end) in some newer devices, although most were limited to about $4,000 \mathrm{~Hz}$. The differences were also noted in terms of the device cost, as the low-end PSAPs tend to provide more low-frequency gain, ${ }^{17}$ suggesting limited benefit for adults with high-frequency hearing loss.

THD reveals the percentage of harmonic distortion (nonlinear added overtones) present in hearing device output. The ANSI S3.22 standard for TDH is $3 \%$ maximum. Generally, most of the devices in these published studies meet the standard for harmonic distortion, but a small number of the low-end devices revealed excessively high values (ie, outliers).

EIN is a measure of the internal circuit noise of a hearing device. The ANSI S3.22-1987 standard for EIN is $28 \mathrm{~dB}$ maximum with a tolerance from this standard of $\pm 3 \mathrm{~dB}$ (ANSI 2014). In these published studies, the EIN ranged between 23.85 and 54.48 and 19.8 and $52.9 \mathrm{~dB}$ for PSAPs and OTC devices, respectively. However, only a limited number of devices (ie, 17 of 47 devices) from the four of the studies passed the tolerance level of $28 \mathrm{~dB}$, making EIN the least met criteria by the direct-to-consumer devices.

These studies also evaluated how closely the device gain and output could match a prescribed fitting target for various degrees of hearing loss. Probe microphone measurements on the KEMAR were used to verify how closely these devices could match a prescription target (ie, NAL-NL2) for various degrees of hearing loss. Results of these studies varied greatly with a few devices matching target gain within $3 \mathrm{~dB}$ for mildto-moderate high-frequency hearing losses, while the majority missed the prescribed fitting target by more than $10 \mathrm{~dB}$ and had limited high-frequency gain. Generally, the lower-end (ie, low-cost) direct-to-consumer hearing devices were found to be of poor electroacoustic quality, and thus, of no value to individuals with mild-to-moderate hearing loss. On the other hand, a few of the higher-end products performed electroacoustically very similar to traditional hearing aids.

\section{Survey of consumers}

The literature search identified five reports that have results of consumer surveys. Two of these were published in nonpeer-reviewed professional magazines, while the remaining three were included in consumer survey reports.

MarkeTrak VIII estimates suggested that about 3.3\% of hearing aid owners received their device through direct-mail orders and $4.4 \%$ of hearing aid non-adopters own PSAPs. ${ }^{27}$ Internet-based consumer survey conducted by the Consumer Electronic Association (today known as the Consumer Technology Association) in the US suggested that only a small portion of those diagnosed with hearing loss (ie, 6\%) and those with at least some trouble hearing (ie, $4 \%$ ) own PSAPs. ${ }^{28}$ Large-scale consumer surveys in Japan indicated that substantial amount (ie, 14\%-19\%) of hearing aid owners purchase their devices through direct-mail or online sources. ${ }^{29,30}$

MarkeTrak data revealed some differences in demographic factors between hearing aid and direct-to-consumer hearing device owners. Direct-mail and PSAP owners were more likely to be male, older, retired, lower income, more experienced hearing aid users, less likely to buy binaural hearing aids, and limited users (ie, 3 hours per day, compared to 10 hours per day with custom hearing aids)..$^{27,31}$ Two-thirds (ie, nearly $75 \%$ ) of direct-mail and PSAP owners were candidates for custom hearing aids, although estimates suggested that less than $18 \%$ of users substitute PSAPs for custom hearing aids. ${ }^{31}$ Also, it appears that the current PSAP owners mainly use them for listening to TV. However, those who were interested in purchasing PSAPs were keen to explore its use for wider situations in daily life..$^{28}$

Exploratory analysis of survey data indicates that satisfaction with hearing aids purchased online is lower than those who purchased in hearing aid centers. ${ }^{30}$ One important factor could be the professional guidance and support. Direct-mail hearing aids provided significantly less real-world benefit than hearing aids dispensed by professionals who adhere to the highest levels of best practice. ${ }^{31}$ However, consumers believe both direct-mail and traditional hearing aids provide equal benefit. Additionally, some consumers were willing to make trade-offs in benefit for substantial cost reduction. ${ }^{31}$

\section{Outcome evaluation}

The literature review identified two studies, published in peer-reviewed journals that evaluated the outcome of OTC hearing aids. ${ }^{32,33}$ Another study examined the preference between PSAPs and hearing aids in a laboratory condition. ${ }^{34}$ In addition, Tedeschi and Kihm, ${ }^{35}$ in a professional magazine article, examined the consumer reaction and 
behavior about direct-to-consumer devices with and without professional consultation.

McPherson and Wong ${ }^{32}$ evaluated the effectiveness of a low-cost OTC hearing aid (ie, ReSound Avance HE4, which costs approximately US \$125) in elderly people with mildto-moderate hearing loss in Hong Kong. Specifically, they focused on objective aided hearing measures and subjective self-reported performance and benefit. Nineteen older adults used the OTC device for a 3-month period. Participants underwent aided hearing threshold and real-ear insertion gain measurements. In addition, they completed self-report measures related to hearing aid outcome, and participated in an open-end interview. The comparison between target and actual insertion gain measures suggested that the OTC device provided satisfactory gain in 2,000 and $4,000 \mathrm{~Hz}$, but under-amplified at $1,000 \mathrm{~Hz}$ (4.65-dB difference from target gain). Most of the participants indicated that the device provided benefits, and all of the participants rated the device as "worth the trouble" of wearing. Sixteen of the 19 participants used the device 1-8 hours a day. The outcome of all three self-reported measures indicated that there were some benefits from using the device. The interview highlighted some benefits (eg, lightweight, invisible device, improvement of hearing ability, feeling of greater security and happiness) and shortcomings (eg, difficult to handle the device, hearing aid-related problems such as feedback, and not clear at close distance) of the device.

More recently, Sacco et $\mathrm{al}^{33}$ studied the clinical value of a newly developed OTC device (ie, TEO First ${ }^{\circledR}$ which costs approximately US \$250) for elderly people with mildto-moderate hearing loss in France. Participants were fitted with the device following a detailed audiological test and instructions. Thirty-one participants used the OTC device for a 1-month period. An outcome assessment was performed before fitting the device and following 1-month use of the device. The outcome assessment included a self-reported measure on quality of life, a survey on acceptability of the device, and overall satisfaction. Quality-of-life improvements were noted in terms of the decrease of perceived hearing difficulties in decreased negative emotions while watching TV, during conversation without background noise, during conversations in noise backgrounds, and during conversation with several people. Self-reports of average daily time use of the device was 60 minutes. Although these benefits were noted and no adverse events were reported during the study, the acceptability of the device was low to moderate.

$\mathrm{Xu}$ et $\mathrm{al}^{34}$ examined the preferences towards PSAPs and hearing aids, of adults with hearing loss, for different listening sounds, processed by these devices, in a laboratory condition. Twenty-three adults with mild-to-moderate hearing loss participated in a listening task and provided preference ratings on three stimuli (ie, speech - dialogue in quiet, everyday noises, and music) with three different device conditions (ie, two premium BTE hearing aids, two basic BTE hearing aids, and two high-quality PSAPs). Hearing aids (combined) were preferred more significantly by participants when compared to PSAPs for speech sounds, whereas no differences in preferences were noted for environmental noises and music. The authors suggested that different devices process some types of sounds more effectively than others. The main limitation of this study is that the devices were fit to an average hearing loss without individualizing the settings and some advanced features (eg, directional microphones, vented earmolds) on the hearing aids were turned off. While these results provide interesting observations, caution must be taken in generalizing the results to real-life settings.

In a recent pilot study, Tedeschi and $\mathrm{Kihm}^{35}$ examined how consumers react to and behave in relation to direct-toconsumer devices with and without professional consultation. Over a 12-week time window, divided into two 6-week phases, their study compared a group of consumers' experience with OTC products (Phase 1) to the traditional service delivery model (Phase 2 ) in which a professional directs the care. The study participants included 29 older adults (aged 60 or over) with mild-to-moderate hearing loss. Although it appears that none of the study participants were directly asked to self-identify any possible red-flag conditions, four of the 29 individuals (13\%) were referred to a physician for a possible medical condition. Also, one participant was excluded from the study because of an outer ear infection based on a preliminary screening before purchasing hearing devices. Twenty-nine eligible study participants completed Phase 1 of the pilot by using a self-selected PSAP or ready-to-wear hearing aid for 6 weeks. At the end of their 6 -week trial with the OTC product/process, about half reported that the OTC device helped some or all of the time, and reported willingness to recommend one to a friend who had a hearing problem. Notably, another one-quarter of the group stopped using OTC devices entirely during Phase 1 . Phase 2 of the study, which involved direct care with a hearing care professional, was completed by 18 of the 26 participants. Although the details of the participants' interaction with the professional were not disclosed in the article, each participant had their level of usage, expectations, and satisfaction measured twice, 3 weeks and 6 weeks post-intervention. Results indicated that $83 \%$ were satisfied with the provider-driven fit, compared 
to $48 \%$ who were satisfied with the OTC device fitting. The article did not report if these differences in outcome between the two phases were of statistical or practical significance.

\section{Quality analysis of existing literature}

Due to limited number of publications in this area, all studies published in both peer-reviewed and non-peer-reviewed journals, consumer surveys, and conference papers were included. The studies on electroacoustic characteristics have used conventional study designs with test box measures and simulated real-ear measures in the KEMAR. The consumer surveys generally used convenience sampling, which may have resulted in sampling bias. In addition, studies on patient outcomes with these devices used open-trial design without a control group or blinding. This may have resulted in some bias as hearing aid research has a documented placebo effect. ${ }^{36}$ Although no structured analysis of quality was performed, the study design of existing literature in this area was found to be generally poor. Further, the studies cited here have higher chances of bias due to the sampling method used and lack of blinding of either the participants or the researchers.

\section{Discussion}

\section{Summary of main findings}

The current systematic literature review was aimed at investigating the applications of direct-to-consumer hearing devices for adults with hearing loss. The studies on direct-to-consumer hearing devices fell into three themes: 1) electroacoustic characteristics, 2) consumer surveys, and 3) outcome evaluation.

The analysis of physical characteristics based on test box and simulated real-ear measures suggested high variability in terms of electroacoustic characteristics. Of particular note, although most of these devices have an OSPL90 of 110- to 120-dB SPL, some were over 130-dB SPL. High outputs are problematic for the direct-to-consumer approach, as a high output can be potentially harmful, especially for ear canals with smaller physical dimensions. Moreover, most of the devices analyzed in these articles showed peak gain and output response at around 1,400-2,000 Hz suggesting limited benefit for adults with high-frequency hearing loss (eg, presbycusis). The analysis of TDH values suggested that most of the devices, including the low-end devices, were well within the suggested 3\% tolerance, with a few low-end devices producing excessively high harmonic distortion (Table 3 ). In addition, most of the devices seem to have high degree of internal noise (ie, EIN $>28 \mathrm{~dB}$ ). A device with a high internal noise floor may be problematic, especially for individuals with normal hearing or mild loss, as circuit noise exceeding $30 \mathrm{~dB}$ may be audible and even bothersome. High circuit noise is not confined to PSAPs and OTC hearing aids. A recent report by Holder et $\mathrm{al}^{37}$ indicated that a high number of traditional hearing aids are also prone to equivalent input (circuit) noise that exceeds the ANSI standard.

The consumer surveys reviewed here suggest that less than $5 \%$ of people with hearing loss in the US purchase directmail hearing aids, ${ }^{27}$ whereas in Japan, up to $19 \%$ of hearing aid owners purchase devices through direct-mail or online. ${ }^{30}$ Thus, it seems apparent that demographic differences exist between those who own direct-to-consumer hearing devices when compared to those who own traditional custom hearing aids. ${ }^{27,31}$ Also, direct-mail hearing aids and PSAPs were associated with lower satisfaction when compared to hearing aids that were purchased through hearing health care professionals. ${ }^{30,31}$ While these results are interesting, it is important to note that most of these surveys were specifically not focused on direct-to-consumer hearing devices; therefore, these observations are rather spurious.

The studies on outcome evaluation suggested that the OTC devices appear to have some benefit for elderly people with mild-to-moderate hearing loss. ${ }^{32,33}$ These benefits ranged from improved hearing in quiet and in noisy situations, improved communication, and activities of daily living. The acceptability ratings were low to moderate in one study conducted in France, ${ }^{33}$ whereas the study in Hong Kong had higher acceptability ratings. ${ }^{32}$ One unpublished laboratory study identified that the hearing aids were preferred more significantly than PSAPs for listening to speech, although no preferences were noted for listening to everyday noises and music. ${ }^{34}$ On a different note, a recent study has reported positive attitude and likely benefits of PSAPs on adults with normal hearing. ${ }^{38}$ However, both studies did not have a control group, and the outcomes were evaluated on a shortterm basis (ie, 1-3 months). Hence, the outcome of these studies should be considered as preliminary findings and interpreted with caution.

\section{Cost of the device}

Cost of the device seems to be a factor in terms of quality and appropriateness of the device for people with hearing loss. For example, low-end (or low-cost) direct-to-consumer hearing devices were poorer in regard to electroacoustic characteristics. ${ }^{24,26}$ In addition, studies suggest that lessexpensive direct-to-consumer hearing devices did not meet 
the gain levels necessary for appropriate amplification of simulated mild-to-moderate hearing loss. ${ }^{17,25}$ Hence, consumers and clinicians should bear in mind that at this stage, the lowest-price device may not be the most appropriate.

\section{Role of hearing health care professionals}

Despite the potential benefits of these direct-to-consumer devices, there is some concern in the audiology community that these devices will disrupt the hearing aid market and may result in a more limited demand for clinical care. However, it is important to note that professional services provided by audiologists are found to be one of the biggest differentiating factors in terms of hearing aid success, as indicated by the MarkeTrak VIII report. ${ }^{39}$ This is further supported by a recent pilot study, which indicated that participants exposed to both the direct-to-consumer and professional-driven delivery systems experience higher satisfaction scores when working directly with a professional. ${ }^{35}$ Another recent qualitative study evaluated the Internet-based delivery of hearing aids, and showed that a large number of study participants reported to have missed the building of trust, value guidance, and expertise of hearing health care professionals. ${ }^{40}$

MarkeTrak VIII survey estimates suggest that less than $18 \%$ of PSAP users substituted PSAPs for custom hearing aids, suggesting that in the absence of such direct-toconsumer hearing devices, those individuals would have lived with hearing loss without any hearing device. ${ }^{39}$ Taken together, these observations suggest that there is a continuing need for audiology services even after a hearing aid market disruption spurred by the availability of direct-to-consumer hearing devices.

\section{Potential advantages and limitations of direct-to-consumer hearing devices}

Direct-to-consumer hearing devices may have various benefits and limitations. ${ }^{19}$ From the professional literature, however, it is evident that wide ranges of opinions have been expressed. While some experts in the field have identified benefit and opportunities, ${ }^{16,23}$ others have concerns about the limitations of the direct-to-consumer model. ${ }^{41}$ The regulatory changes in relation to direct-to-consumer hearing devices could potentially open the new market and provide accessibility to various individuals who would not seek help and intervention through traditional channels. ${ }^{23}$ It could greatly reduce the time and money associated with purchasing and using a hearing device. Moreover, as many of these devices are not called hearing aids (eg, PSAPs) and look more like consumer electronic devices than hearing aids, it may reduce stigma associated with the hearing aid image. ${ }^{42}$ On the other hand, there are also potential disadvantages. First, there is potential risk with the direct-to-consumer model that some individuals with red-flag conditions (eg, sudden deafness, acute or chronic dizziness) who would require medical investigations may not have the opportunity to undergo screening by a hearing health care specialist. Second, users of such devices, if fitted inappropriately, may experience dangerously high sound levels, and they may be at risk of developing further hearing damage and symptoms such as tinnitus. ${ }^{41}$ Third, initial bad experiences with inappropriate use of such devices may keep those individuals away from consulting hearing health care professionals, although there is no published data to support this claim. Conversely, some individuals may use these devices as a gateway instruments to actual hearing aids. ${ }^{18}$

\section{Future directions}

There is some move towards developing self-fitting hearing aids, which may disrupt and alter innovation in hearing health care. ${ }^{43,44}$ However, research on direct-to-consumer hearing devices is still in its infancy. Today is probably one of the most interesting times in the hearing industry as the landscape is changing quickly due to the rapid advancement of amplification technology as well as to potential changes in federal regulations of the hearing aid market.

It is important to differentiate between traditional hearing aids and the direct-to-consumer hearing devices, not only in terms of device characteristics but also in terms of expected patient outcomes. Also, it is important to differentiate the devices that produce the best patient outcomes across various listening situations. ${ }^{34}$ Moreover, the full scope of direct-toconsumer hearing devices may have been overlooked in this manuscript, as we do not include personalized amplification through mobile phones. At this point, it is too early to know if smartphone-based apps will be an integral part of a dedicated self-fitting hearing aid or simply allow the end user to control a variety of amplification devices through any number of apps. However, some recent evidence suggests that the smartphone-based amplification app has the potential to improve speech recognition for people with mild-to-moderate hearing loss, as well as people with normal hearing. ${ }^{45}$

There is a great need to develop an evidence base with well-controlled and more imaginative studies in relation to direct-to-consumer hearing devices. This could range from determining the candidacy to studying the user experience, outcome, and economic evaluation. Table 4 provides some specific areas that researchers and clinicians 
Table 4 Areas to focus while investigating direct-to-consumer hearing devices

\begin{tabular}{|c|c|}
\hline Domain & Specific area \\
\hline \multirow[t]{2}{*}{ Selection and candidacy } & Define a specific group of individuals \\
\hline & Define the context of use \\
\hline \multirow[t]{4}{*}{ Expectations } & Does lower costs correlate to lower \\
\hline & expectation \\
\hline & Differences between traditional and \\
\hline & direct-to-consumer products \\
\hline \multirow{3}{*}{$\begin{array}{l}\text { Acoustic physical fact finding } \\
\text { (ie, electroacoustic measures) }\end{array}$} & Test box and coupler measurements \\
\hline & Simulated real-ear measures using a \\
\hline & KEMAR \\
\hline \multirow[t]{2}{*}{ Verification } & Real ear measures \\
\hline & Functional gain \\
\hline \multirow[t]{5}{*}{ User experience and perception } & Fitting comfort \\
\hline & Image perception \\
\hline & Decision-making process of \\
\hline & consumers \\
\hline & Use and maintenance of the device \\
\hline \multirow[t]{7}{*}{ Outcome evaluation dimensions } & Perceived hearing disability \\
\hline & Speech perception in quiet \\
\hline & Speech perception in noise \\
\hline & Communication ability \\
\hline & Activities and participation \\
\hline & Health-related quality of life \\
\hline & Tinnitus distress \\
\hline \multirow{6}{*}{$\begin{array}{l}\text { Factors that may influence the } \\
\text { outcome }\end{array}$} & Socioeconomic status \\
\hline & Cost of the device \\
\hline & Health literacy \\
\hline & Guidance and support from hearing \\
\hline & health care professional \\
\hline & Aural rehabilitation \\
\hline \multirow[t]{4}{*}{ Economic evaluation } & Cost analysis \\
\hline & Cost-benefit analysis \\
\hline & Cost-effectiveness analysis \\
\hline & Cost-utility analysis \\
\hline
\end{tabular}

Abbreviation: KEMAR, Knowles Electronics Mannequin for Acoustic Research.

could consider while investigating the direct-to-consumer hearing devices.

\section{Conclusion}

Direct-to-consumer hearing devices, a category of products comprising PSAPs, direct-mail hearing aids, and OTC hearing aids, have caught the attention of various stakeholders, including audiologists, public health officials, physicians, and consumers. Their rise in popularity appears to be driven by technological advancements in amplification, consumer demand, and suggestions made by federal government advisory boards. Currently, there is limited evidence on the applications of direct-to-consumer hearing devices for people with hearing loss. Our literature identified studies on direct-to-consumer hearing devices, which fall into three general themes: 1) electroacoustic characteristics compared to traditional hearing aids, 2) consumer surveys, and 3) patient outcome evaluation. Although some devices have the capability to cause adverse effects due to high output sound levels and internal noise they produce, the existing literature suggests that there are some potential benefits of direct-to-consumer hearing devices. The research on directto-consumer hearing devices is limited, and the quality of current studies is weak. Much effort is needed to understand the benefits and limitations of such devices on people with hearing loss.

\section{Disclosure}

The authors report no conflicts of interest in this work.

\section{References}

1. World Health Organization. Deafness and hearing loss fact sheet. Geneva: WHO; 2015. Available from: http://www.who.int/mediacentre/ factsheets/fs300/en/. Accessed December 1, 2016.

2. Lin FR, Yaffe K, Xia J, et al; Health ABC Study Group. Hearing loss and cognitive decline in older adults. JAMA Intern Med. 2013;173(4): 293-299.

3. Hsu WT, Hsu CC, Wen MH, et al. Increased risk of depression in patients with acquired sensory hearing loss: a 12-year follow-up study. Medicine (Baltimore). 2016;95(44):e5312.

4. Dawes P, Emsley R, Cruickshanks KJ, et al. Hearing loss and cognition: the role of hearing AIDS, social isolation and depression. PLoS One. 2015;10(3):e0119616.

5. Lin FR, Metter EJ, O'Brien RJ, Resnick SM, Zonderman AB, Ferrucci L. Hearing loss and incident dementia. Arch Neurol. 2011; 68(2):214-220.

6. Lopez D, McCaul KA, Hankey GJ, et al. Falls, injuries from falls, health related quality of life and mortality in older adults with vision and hearing impairment is there a gender difference? Maturitas. 2011; 69(4):359-364.

7. World Health Organization. Hearing loss in persons 65 years and older. WHO global estimates on prevalence of hearing loss, mortality and burden of diseases and prevention of blindness and deafness. Geneva: WHO; 2012. Available from: http://www.who.int/pbd/deafness/news/ GE_65years.pdf. Accessed May 2, 2017.

8. Olaosun A, Ogundiran O. Hearing loss and the elderly - a primer. J Natl Sci Res. 2013;3(13):171-175.

9. Donahue A, Dubno JR, Beck L. Accessible and affordable hearing health care for adults with mild to moderate hearing loss. Ear Hear. 2010;31(1):2-6.

10. National Academies of Sciences, Engineering, and Medicine. Hearing health care for adults: priorities for improving access and affordability. Washington, DC: The National Academies Press; 2016. Available from: http://www.nationalacademies.org/hmd/Reports/2016/Hearing-HealthCare-for-Adults.aspx. Accessed December 1, 2016.

11. Chien W, Lin FR. Prevalence of hearing aid use among older adults in the United States. Arch Intern Med. 2012;172(3):292-293.

12. Mamo SK, Nieman CL, Lin FR. Prevalence of untreated hearing loss by income among older adults in the United States. $J$ Health Care Poor Underserved. 2016;27(4):1812-1818.

13. Kochkin S. MarkeTrak VIII: the key influencing factors in hearing aid purchase intent. Hear Rev. 2012;19(3):12-25.

14. Contrera KJ, Wallhagen MI, Mamo SK, Oh ES, Lin FR. Hearing loss health care for older adults. J Am Board Fam Med. 2016;29(3):394 403.

15. Convery E, Keidser G, Seeto M, McLelland M. Evaluation of the self-fitting process with a commercially available hearing aid. $J \mathrm{Am}$ Acad Audiol. 2017;28(2):109-118. 
16. Taylor B. Hearables: the morphing of hearing aids consumer electronic devices. Audiol Today. 2015;27(6):22-30.

17. Smith C, Wilber LA, Cavitt K. PSAPs vs hearing aids: an electroacoustic analysis of performance and fitting capabilities. Hear Rev. 2016; 23(7): 18 .

18. Stump E. The pros and cons of PSAPs. Hearing Health (Spring). 2016:20-22.

19. Mamo SK, Reed NS, Nieman CL, Oh ES, Lin FR. Personal sound amplifiers for adults with hearing loss. Am J Med. 2016;129(3): 245-250.

20. Hunn N. The market for smart Wearables 2014-2020: a consumer centric approach. London: WiForce Wireless Consulting; 2014 Available from: http://www.nickhunn.com/wp-content/uploads/ downloads/2014/08/The-Market-for-Smart-Wearables.pdf. Accessed November 20, 2016.

21. Hunn N. The market for hearable devices 2016-2020. London: WiForce Wireless Consulting; 2016. Available from: http://www.nickhunn.com/ wp-content/uploads/downloads/2016/11/The-Market-for-HearableDevices-2016-2020.pdf. Accessed December 1, 2016.

22. Lin FR, Hazzard WR, Blazer DG. Priorities for improving hearing health care for adults: a report from the National Academies of Sciences, Engineering, and Medicine. JAMA. 2016;316(8):819-820.

23. Blustein J, Weinstein BE. Opening the market for lower cost hearing aids: regulatory change can improve the health of older Americans. Am J Public Health. 2016;106(6):1032-1035.

24. Cheng CM, McPherson B. Over-the-counter hearing aids: electroacoustic characteristics and possible target client groups. Audiology. 2000;39(2):110-116

25. Callaway SL, Punch JL. An electroacoustic analysis of over-the-counter hearing aids. Am J Audiol. 2008;17(1):14-24.

26. Chan ZYT, McPherson B. Over-the-counter hearing aids: a lost decade for change. Biomed Res Int. 2015;2015:827463.

27. Kochkin S. MarkeTrak VIII: utilization of PSAPs and direct-mail hearing aids by people with hearing impairment. Hear Rev. 2010; 17(6):12-16

28. Consumer Electronic Association. Personal sound amplification products: a study of consumer attitudes and behavior. 2014. Available from: http://www.hearingloss.org/content/psaps-consumer-attitudes. Accessed November 20, 2016

29. JapanTrak. Hearing aid market in Japan. European Hearing Instrument Manufacturers Association; 2012. Available from: http://www.ehima. com/wp-content/uploads/2016/02/JAPAN_Trak_2015-1.pdf. Accessed November 20, 2016.

30. JapanTrak. Hearing aid market in Japan. European Hearing Instrument Manufacturers Association; 2015. Available from: http://www.ehima. com/wp-content/uploads/2016/02/JAPAN_Trak_2015-1.pdf. Accessed November 20, 2016.
31. Kochkin S. A comparison of consumer satisfaction, subjective benefit and quality of life changes associated with traditional and direct-mail hearing aid use. Hear Rev. 2014;21(1):16-26.

32. McPherson B, Wong ET. Effectiveness of an affordable hearing aid with elderly persons. Disabil Rehabil. 2005;27(11):601-609.

33. Sacco G, Gonfrier S, Teboul B, et al. Clinical evaluation of an overthe-counter hearing aid (TEO First ${ }^{\mathbb{1}}$ ) in elderly patients suffering of mild to moderate hearing loss. BMC Geriatr. 2016;9(16):136.

34. Xu J, Johnson J, Cox R, Breitbart D. Laboratory comparison of PSAPs and hearing aids. Paper presented at: Annual Meeting of the American Auditory Society; March 2015; Scottsdale, AZ.

35. Tedeschi TJ, Kihm J. Implications of an over-the-counter approach to hearing healthcare: a consumer study. Hear Rev. 2016. Available from: http://www.hearingreview.com/2016/12/implications-counter-approachhearing-healthcare-consumer-study/. Accessed January 1, 2017.

36. Dawes P, Hopkins R, Munro KJ. Placebo effects in hearing-aid trials are reliable. Int J Audiol. 2013;52(7):472-477.

37. Holder JT, Picou EM, Gruenwald JM, Rickeets TA. Do modern hearing aids meet ANSI standards? J Am Acad Audiol. 2016;27(8):619-627.

38. Rhoades J. Attitudes of normal hearing listens towards personal sound amplification products: Etymotic Bean. New York: City University of New York (CUNY); 2015. Available from: http://academicworks.cuny. edu/cgi/viewcontent.cgi?article $=1654 \&$ context $=$ gc_etds. Accessed November 20, 2016

39. Kochkin S, Beck DL, Christensen LA, et al. MarkeTrak VIII: the impact of the hearing healthcare professional on hearing aid user success. Hear Rev. 2010;17(4):12-34.

40. Chandra N, Searchfield G. Perceptions towards Internet-based delivery of hearing aids among older hearing-impaired adults. J Am Acad Audiol. 2016;27(6):441-457.

41. Handelsman J. Over-the-counter hearing devices could make hearing worse: a recommendation by the National Academy of Sciences is off the mark. Rockville, MD: American Speech-Language Hearing Association; 2016. Available from: http://www.asha.org/About/news/ Press-Releases/2016/Over-the-Counter-Hearing-Devices-Could-MakeHearing-Worse/. Accessed December 1, 2016.

42. Manchaiah V, Danermark B, Vinay, et al. Social representation of hearing aids: cross-cultural study in India, Iran, Portugal and United Kingdom. Clin Interv Aging. 2015;10:1601-1615.

43. Convery E, Keidser G, Dillon H, Hartley L. A self-fitting hearing aid: need and concept. Trends Amplif. 2011;15(4):157-166.

44. Keidser G, Convery E. Self-fitting hearing aids: status quo and future predictions. Trends Hear. 2016;20.

45. Kam AC, Sung JK, Lee T, Wong TK, van Hasselt A. Improving mobile phone speech recognition by personalized amplification: application in people with normal hearing and mild-to-moderate hearing loss. Ear Hear. 2017;38(2):e85-e92.
Clinical Interventions in Aging

\section{Publish your work in this journal}

Clinical Interventions in Aging is an international, peer-reviewed journal focusing on evidence-based reports on the value or lack thereof of treatments intended to prevent or delay the onset of maladaptive correlates of aging in human beings. This journal is indexed on PubMed Central, MedLine,

\section{Dovepress}

CAS, Scopus and the Elsevier Bibliographic databases. The manuscript management system is completely online and includes a very quick and fair peer-review system, which is all easy to use. Visit http://www.dovepress. com/testimonials.php to read real quotes from published authors. 